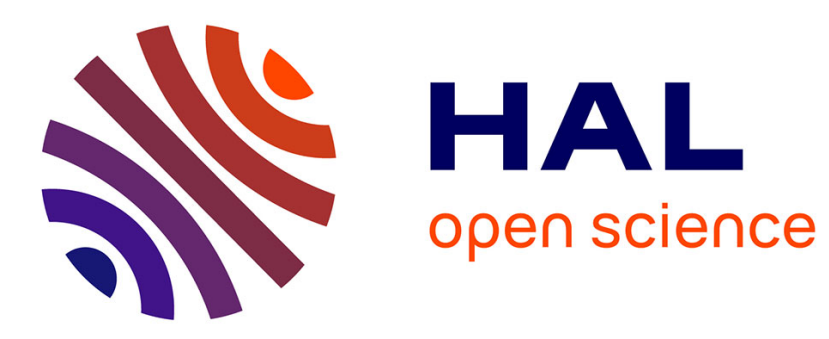

\title{
Validation tests of the W2020 energy levels of water vapor
}

\author{
A. Campargue, S.N. N Mikhailenko, S. Kassi, S. Vasilchenko
}

\section{To cite this version:}

A. Campargue, S.N. N Mikhailenko, S. Kassi, S. Vasilchenko. Validation tests of the W2020 energy levels of water vapor. Journal of Quantitative Spectroscopy and Radiative Transfer, 2021, 276, pp.107914. 10.1063/5.0030680] . hal-03433137

\section{HAL Id: hal-03433137 https://hal.science/hal-03433137}

Submitted on 17 Nov 2021

HAL is a multi-disciplinary open access archive for the deposit and dissemination of scientific research documents, whether they are published or not. The documents may come from teaching and research institutions in France or abroad, or from public or private research centers.
L'archive ouverte pluridisciplinaire HAL, est destinée au dépôt et à la diffusion de documents scientifiques de niveau recherche, publiés ou non, émanant des établissements d'enseignement et de recherche français ou étrangers, des laboratoires publics ou privés. 


\section{Validation tests of the W2020 energy levels of water vapor}

A. Campargue ${ }^{a *}$, S.N. Mikhailenko ${ }^{b, c}$, S. Kassi ${ }^{a}$, S. Vasilchenko ${ }^{b}$

${ }^{a}$ Univ. Grenoble Alpes, CNRS, LIPhy, 38000 Grenoble, France

${ }^{b}$ V.E. Zuev Institute of Atmospheric Optics, SB, Russian Academy of Science, 1, Academician Zuev square, 634055 Tomsk, Russia

c Climate and Environmental Physics Laboratory, Ural Federal University, 19, Mira av., 620002 Yekaterinburg, Russia

Key words: water vapor; $\mathrm{H}_{2} \mathrm{O}$; absorption spectroscopy; rovibrational energy level; MARVEL; spectroscopic database

Number of Pages: $\quad 20$

Number of Figures: 6

Number of Tables: 1

Corresponding author.

E-mail address: Alain.Campargue@univ-grenoble-alpes.fr

Tel.: 33476514319 Fax. 33476635495 


\begin{abstract}
A decade ago, a task group (TG) of the International Union of Pure and Applied Chemistry (IUPAC) performed an exhaustive collection and review of measured transitions, applied the MARVEL procedure, and derived recommended empirical energy levels for nine major water isotopologues. Very recently, using an improved methodology, the sets of empirical energy levels of $\mathrm{H}_{2}{ }^{16} \mathrm{O}, \mathrm{H}_{2}{ }^{18} \mathrm{O}$ and $\mathrm{H}_{2}{ }^{17} \mathrm{O}$ were updated, leading to the so-called W2020 energy levels and transition wavenumbers [Furtenbacher et al. J. Phys. Chem. Ref. Data 49 (2020) 043103; https://doi.org/10.1063/5.0030680].

Here we present validation tests of the W2020 line list of $\mathrm{H}_{2}{ }^{16} \mathrm{O}$ against spectra recorded by cavity ring down spectroscopy (CRDS) referenced to a frequency comb (FC), newly recorded in the 8040$8630 \mathrm{~cm}^{-1}$ region. The recorded spectra are found in excellent agreement with previous high-quality studies available in the literature. While these literature sources were all incorporated in the transition database used to derive the W2020 energy levels, the direct superposition of the FC-CRDS spectra to the W2020 line list of $\mathrm{H}_{2}{ }^{16} \mathrm{O}$ shows a number of large disagreements. Cases where deviations largely exceeding the W2020 claimed uncertainty on the transition frequencies are noted. The resulting W2020 list is thus less accurate than some of the published original sources used to derive the W2020 energy levels. We conclude that the sophisticated global procedure and algorithm elaborated to identify and adequately weight inaccurate line positions among the large W2020 transition database do not always prevent less accurate data from "spoiling" higher quality data sources.

The W2020 list of $\mathrm{H}_{2}{ }^{16} \mathrm{O}$ is also compared to newly recorded CRDS spectra in the 13000-13200 $\mathrm{cm}^{-1}$ region (corresponding to the region of the A-band of $\mathrm{O}_{2}$ ), where previous observations were very scarce. In the same way, as in the previous region, substantial position deviations are evidenced, and in many cases, the W2020 error bars appear to be strongly underestimated.
\end{abstract}




\section{Introduction}

Transition frequencies corresponding to the energy differences between two energy levels, a given energy level can be involved in many absorption or emission lines. The determination of its energy is thus expected to benefit from the measured frequencies of the various transitions sampling the considered level. The idea of inverting transition frequencies to derive energy levels is closely related to the Rydberg-Ritz combination principle established for the hydrogen atom [1]. The method can also be applied to derive empirical rovibrational energy values from transition frequencies provided by highresolution molecular spectra [2,3]. The MARVEL (Measured Active Rotational-Vibrational Energy Levels) methodology has been developed for this purpose [4,5]. Due to the major importance of the water molecule, over a decade ago, the International Union of Pure and Applied Chemistry (IUPAC) supported the project "A database of water transitions from experiment and theory", largely devoted to the determination of recommended values for rovibrational energy levels of the main isotopologues of water. The IUPAC- task group (TG) first task was to perform an exhaustive review and evaluation of rovibrational line positions available in the literature. Then, for each isotopologue, the procedure and code MARVEL were applied to the constructed catalog of published absorption and emission line positions and recommended sets of energy levels were released for each isotopologue, with their selfconsistent uncertainties [6-9]. For instance, for the main isotopologue, $\mathrm{H}_{2}{ }^{16} \mathrm{O}, 184,667$ transitions were gathered from 97 literature sources, and 18,486 energy levels were derived [8]. As a result of the considerable differences in the line position accuracies, the uncertainties (often unreported) were estimated by the MARVEL procedure and used to weight the corresponding line positions.

Very recently, the group maintaining MARVEL energy levels reported an update of the IUPACTG energy levels for $\mathrm{H}_{2}{ }^{16} \mathrm{O}, \mathrm{H}_{2}{ }^{18} \mathrm{O}$, and $\mathrm{H}_{2}{ }^{17} \mathrm{O}[10,11]$. The so-called $\mathrm{W} 2020$ energy levels benefited from a series of recent high-quality measurements and from improvements in the MARVEL protocol (xMARVEL) with the introduction of cycles and segments $[10,12,13]$. As a result, the $\mathrm{W} 2020-\mathrm{H}_{2}{ }^{16} \mathrm{O}$ transition dataset gathers 286,987 non-redundant rovibrational transitions, and 19,225 empirical energy levels were determined with corresponding uncertainties [11]. The new xMARVEL protocol has been improved to better evaluate and take into account the uncertainties with the introduction of estimated segment uncertainty (ESU), recalibration of the line positions of some sources, and "weighted leastsquares refinement of the line uncertainties built upon consecutive addition of transition blocks of decreasing accuracy leading to highly accurate empirical energy values" [10].

The identification and adequate weighting of nearly 300,000 line positions of about 200 sources, as was done for the $\mathrm{H}_{2}{ }^{16} \mathrm{O}$ isotopologue, is a real challenge. It has led to a high sophistication in the developed procedure in order to treat sources with very different quality globally (from Lamb dip measurements to emission spectroscopy at medium resolution, from the microwave to the UV). While the algorithms and the amount and quality of the input data have been improved, there are a lot of issues that are very hard to account for. They include absence or over (and under) estimation of the 
uncertainties in the original works, typographical errors in the original works, and in their implementations into MARVEL, to name a few. Therefore, at the final stage of such a complex process, validation tests of the obtained W2020 line positions by direct comparison to spectra deserve to be performed to check that no biases were introduced in the procedure. Such validations are the object of the present contribution.

During the last years, we have produced a series of spectra analyses of the water isotopologues by cavity ring down spectroscopy (CRDS) in the near-infrared $\left(5690-8340 \mathrm{~cm}^{-1}\right)$ [14-26]. These studies were all included as input data sources in the W2020 transition database. In principle, the MARVEL procedure has been developed to obtain empirical energy levels and transition wavenumbers of higher accuracy than that of each of the original sources. This is indeed the final statement of Ref. [11]: As to the final conclusion of this study, we recommend that both the validated rovibrational transitions and the accurate empirical energy levels of this study should be included in the next generation of line-byline spectroscopic information systems, such as HITRAN. In order to test this recommendation, in this contribution, we directly superimpose our CRDS spectra to the W2020 stick spectra of the main isotopologue, $\mathrm{H}_{2}{ }^{16} \mathrm{O}$, in the $8000-8600 \mathrm{~cm}^{-1}$ interval. From these comparisons, it appears that this recommendation is not justified in the considered spectral region and that in some cases the resulting W2020 lists have an accuracy poorer than some of the original sources included in the MARVEL process.

Recently, we proposed a complete empirical line list (MC2020, hereafter) for water in natural isotopic abundance in the $5690-8340 \mathrm{~cm}^{-1}$ region [27]. In the same way, as done for the W2020 line list, our line positions were obtained from a set of empirical rotation-vibration energy levels. In the considered region, a total of 57,995 energy levels were needed to generate the line list of the first six isotopologues of water vapor in natural isotopic abundance (the intensity cut off at $296 \mathrm{~K}$ was fixed to $5 \times 10^{-30} \mathrm{~cm} /$ molecule). Contrary to the W2020 approach, which considers all available experimental sources (including a large amount of emission data), our upper energy level values rely on a selection of high-resolution absorption studies at room temperature (see Table 2 of Ref. [27]): the CRDS studies of Refs. [14-26, 28-30] including highly accurate measurements by CRDS referenced to a frequency comb [25, 26, 28, 29], Lamb dip measurements [31], FTS studies of Refs. [32-42] and a study by intracavity laser absorption spectroscopy [43] for the deuterated isotopologues. All these sources (30 in total for the main isotopologue) are part of the large transition database managed by the XMARVEL procedure. Note that the MC2020 dataset also includes 4206 IUPAC-TG energy levels adopted after experimental validation [27].

The comparison of the W2020 and MC2020 line positions is discussed in section 2 on the basis of new spectra recorded by CRDS referenced to a frequency comb (FC) in the $8000-8600 \mathrm{~cm}^{-1}$ region. The MC2020 line positions are observed to show better agreement with the spectrum than the W2020 positions not only below $8340 \mathrm{~cm}^{-1}$ where previous CRDS studies were published but also above 8340 
$\mathrm{cm}^{-1}$, where a large number of new transitions are detected. A systematic comparison of the W2020 [11] and MC2020 [27] line positions in the $5690-8340 \mathrm{~cm}^{-1}$ region is included in Section 2 and provided as Supplementary Material.

In Section 3, validation tests are presented at significantly higher energy, near $13000 \mathrm{~cm}^{-1}$ in a region of weak absorption (line intensities smaller than $10^{-26} \mathrm{~cm} /$ molecule). Previous observations in the region are very scarce, and most of the W2020 line positions rely on empirical energy levels determined from transitions located in different spectral regions.

In the conclusion (Section 4), the obtained results are summarized, and we underline the general importance of validation tests against high-quality spectra before recommending spectroscopic line lists obtained by theory or after a complex treatment of a large experimental dataset as performed for the W2020 line lists.

\section{Region $5690-8600 \mathrm{~cm}^{-1}$}

\subsection{W2020 and CRDS spectra in the $8040-8630 \mathrm{~cm}^{-1}$ region}

The water vapor spectrum in the $7911-8337 \mathrm{~cm}^{-1}$ region has been the subject of a previous CRDS study [20]. The present new recordings extending up to $8600 \mathrm{~cm}^{-1}$ were performed in flow regime at a pressure regulated at 1.0 Torr using as light sources two external cavity laser diodes (ECDL) (the one used in Ref. [20] and a new one below and above $8300 \mathrm{~cm}^{-1}$, respectively). The reader is referred to Refs. [25, 44-46] for the description of the cavity ring down spectrometer and the frequency tuning of the ECDL. The accurate frequency value associated to each ring-down event was obtained by using a Fizeau type wavemeter (High Finesse WS-U-30 IR) and a self-referenced frequency comb. The FC referencing (already applied to water vapor spectra in Refs. [25, 26]) makes negligible the line position uncertainty due to the calibration of the frequency axis resulting in error bars mostly determined by the line center determination (typically $10^{-4} \mathrm{~cm}^{-1}$ ). The noise equivalent absorption evaluated as the rms of the baseline fluctuations is around $5 \times 10^{-12} \mathrm{~cm}^{-1}$. A separate publication will be devoted to the systematic analysis of the spectra covering the $8040-8630 \mathrm{~cm}^{-1}$ region. In the $8040-8337 \mathrm{~cm}^{-1}$ interval in common with Ref. [20], the present recordings will allow to slightly extend previous observations and improve the accuracy of the line parameters. Above $8337 \mathrm{~cm}^{-1}$, only FTS studies are available [32, 40, 42] and a considerable number of transitions are newly detected.

We present in Figs. 1 and $\mathbf{2}$ the superposition of the CRDS spectrum to the stick spectra corresponding to the W2020 list of $\mathrm{H}_{2}{ }^{16} \mathrm{O}$ and to the MC2020 and HITRAN2016 [47] lists of natural water. Although the present contribution is focused on line positions, let us mention that the W2020 intensities are the PoKaZaTeL variational values [48]. In contrast, intensity values computed on the basis of the results of Schwenke and Partridge (SP) [49-51] are attached to the MC2020 line positions. The HITRAN2016 list mixes intensity sources with theoretical and experimental origins in the region.

Error bars provided for each W2020 transition wavenumber are plotted in Figs. 1 and 2. In the case of the MC2020 line positions, only rough estimations are available for the position error bars, 
according to the source of the upper level [27]: $10^{-6} \mathrm{~cm}^{-1}$ (Lamb dip), $2 \times 10^{-4} \mathrm{~cm}^{-1}$ (FC-CRDS), 10-3 $\mathrm{cm}^{-1}$ (standard CRDS, FTS and IUPAC-TG), $10^{-2} \mathrm{~cm}^{-1}$ (ICLAS and estimated) and a few tenth of wavenumber for SP variational positions. For the lines displayed in Figs. 1 and 2, the estimated error on the MC2020 positions is on the order of $10^{-3} \mathrm{~cm}^{-1}$. For comparison, the Doppler line width is about 1.2 $\times 10^{-2} \mathrm{~cm}^{-1}(\mathrm{HWHM})$ in the considered spectral region.

The sample of examples, presented in Figs. 1 and 2, show that the MC2020 line positions agree better with the FC-CRDS spectrum than the W2020 positions. Table 1 lists the problematic lines with their different position values, the W2020 position uncertainty, the assignment, and the origin of the MC2020 upper energy values (all the sources are published studies by FTS, CRDS or FC-CRDS). In most of the cases provided in the Table, the deviations of the W2020 position from the observed line center largely exceed the claimed W2020 error bar, sometimes by more than two orders of magnitude (e.g. the position at $8130.0391 \mathrm{~cm}^{-1}$ given with $2.43 \times 10^{-4} \mathrm{~cm}^{-1}$ error bar deviates from the MC2020 value by $\left.2.86 \times 10^{-2} \mathrm{~cm}^{-1}\right)$. It is important to recall that the MC2020 line positions in the region rely mostly on the results of the CRDS study of Ref. [20], which is one of the sources of the W2020 transition database.

As concerns HITRAN2016 line positions [47], they generally agree with the CRDS spectrum and coincide with the MC2020 values because most originate from a first version of the MC2020 list [52].
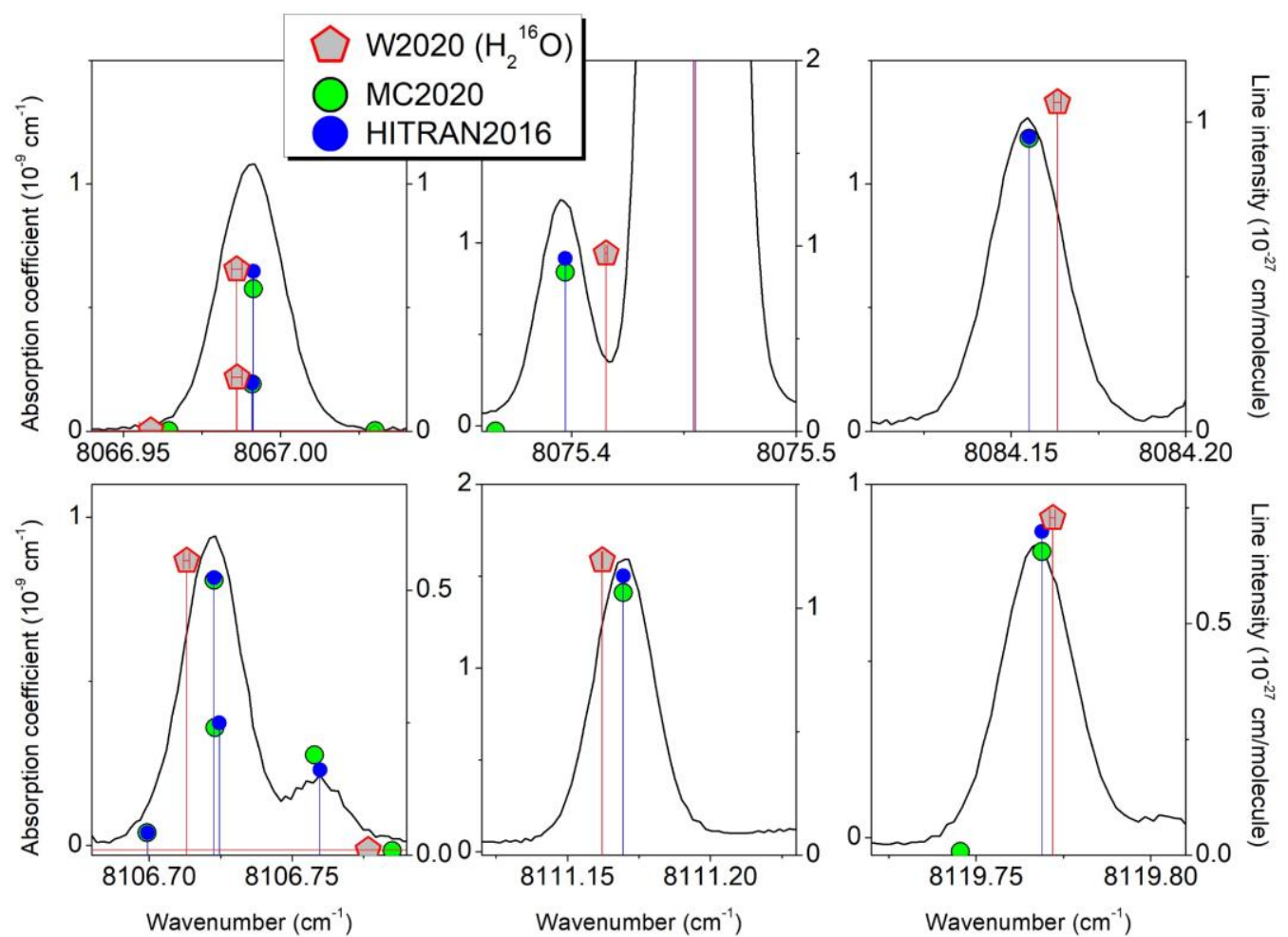

Fig. 1

Examples of discrepancies between the FC-CRDS of water vapor recorded at 1.00 Torr and the W2020 line list of $\mathrm{H}_{2}{ }^{16} \mathrm{O}$ [11] (grey pentagons). The MC2020 [27] and HITRAN2016 [47] lists of natural water are plotted for comparison (green and blue circles, respectively). 
Table 1

Comparison of the $\mathrm{H}_{2}{ }^{16} \mathrm{O}$ transitions showing important position differences, displayed in Figs. 1-3, 6.

\begin{tabular}{|c|c|c|c|c|c|c|c|c|c|c|c|c|c|c|c|c|c|}
\hline \multicolumn{8}{|c|}{$\left(V_{l} V_{2} V_{3}\right) J K a K c$} & \multicolumn{3}{|c|}{ MC2020 [27] } & \multicolumn{2}{|c|}{ HITRAN2016 [47] } & \multicolumn{3}{|c|}{ W2020 [11] } & \multirow{2}{*}{\begin{tabular}{|c|}
$\begin{array}{c}\text { Meas. } \\
\text { (This work) } \\
\text { Position } \\
\left(\mathrm{cm}^{-1}\right)\end{array}$ \\
\end{tabular}} & \multirow{2}{*}{$R^{d}$} \\
\hline \multicolumn{4}{|c|}{ Upper level } & \multicolumn{4}{|c|}{ Lower level } & $\begin{array}{c}\begin{array}{c}\text { Position } \\
\left(\mathrm{cm}^{-1}\right)\end{array} \\
\end{array}$ & $\begin{array}{c}\begin{array}{c}\text { Intensity } \\
\left(\mathrm{cm} / \text { molecule }^{b}\right)\end{array} \\
\end{array}$ & Source ${ }^{c}$ & $\begin{array}{l}\text { Position } \\
\left(\mathrm{cm}^{-1}\right)\end{array}$ & $\begin{array}{c}\text { Intensity } \\
(\mathrm{cm} / \text { molecule })\end{array}$ & $\begin{array}{l}\text { Position } \\
\left(\mathrm{cm}^{-1}\right)\end{array}$ & $\begin{array}{l}\text { Pos. Unc. } \\
\left(\mathrm{cm}^{-1}\right)\end{array}$ & $\begin{array}{c}\text { Intensity } \\
(\mathrm{cm} / \text { molecule })\end{array}$ & & \\
\hline 050 & 8 & 7 & 1 & 000 & 9 & 8 & 2 & \begin{tabular}{|l|}
8066.9909 \\
\end{tabular} & $1.901 \mathrm{E}-28$ & FTS & 8066.990900 & $1.945 \mathrm{E}-28$ & 8066.9861535024 & $1.60 \mathrm{E}-03$ & $2.179 \mathrm{E}-28$ & 8066.99052 & 3 \\
\hline 050 & 8 & 7 & 2 & 000 & 9 & 8 & 1 & 8066.9913 & $5.757 \mathrm{E}-28$ & FTS & 8066.991300 & $6.473 \mathrm{E}-28$ & 8066.9860360875 & $1.66 \mathrm{E}-03$ & $6.538 \mathrm{E}-28$ & 8066.99052 & 3 \\
\hline 031 & 6 & 5 & 2 & 000 & 7 & 7 & 1 & 8075.3973 & $8.581 \mathrm{E}-28$ & CRDS & 8075.397300 & $9.320 \mathrm{E}-28$ & 8075.4154056696 & $6.02 \mathrm{E}-04$ & $9.575 \mathrm{E}-28$ & 8075.39576 & 33 \\
\hline 041 & 2 & 0 & 2 & 010 & 3 & 2 & 1 & 8084.1552 & $9.469 \mathrm{E}-28$ & CRDS & 8084.155200 & $9.510 \mathrm{E}-28$ & 8084.1632629320 & $1.00 \mathrm{E}-03$ & $1.064 \mathrm{E}-27$ & 8084.15461 & 9 \\
\hline 031 & 14 & \begin{tabular}{l|l}
2 & 1
\end{tabular} & 13 & 000 & 15 & 2 & 14 & 8106.7227 & $5.188 \mathrm{E}-28$ & CRDS & 8106.722700 & $5.241 \mathrm{E}-28$ & 8106.7131260397 & $1.03 \mathrm{E}-03$ & $5.560 \mathrm{E}-28$ & 8106.72227 & 9 \\
\hline 050 & 8 & 4 & 5 & 000 & 8 & 3 & 6 & 8111.1696 & $1.063 \mathrm{E}-27$ & FC-CRDS & 8111.169500 & $1.130 \mathrm{E}-27$ & 8111.1621815133 & 1.91E-04 & $1.193 \mathrm{E}-27$ & 8111.16959 & 39 \\
\hline 041 & 6 & 0 & 6 & 010 & 6 & 2 & 5 & 8119.7689 & $6.548 \mathrm{E}-28$ & CRDS & 8119.768900 & $6.980 \mathrm{E}-28$ & 8119.7719282555 & 7.71E-04 & $7.272 \mathrm{E}-28$ & 8119.76747 & 6 \\
\hline 111 & 11 & 6 & 6 & 000 & 12 & 8 & 5 & 8127.2930 & $1.508 \mathrm{E}-28$ & CRDS & 8127.293000 & $1.820 \mathrm{E}-28$ & 8127.2971691295 & $8.55 \mathrm{E}-04$ & $1.605 \mathrm{E}-28$ & 8127.29323 & 5 \\
\hline 050 & 14 & \begin{tabular}{l|l}
4 & 1
\end{tabular} & 11 & 000 & 15 & 1 & 14 & 8130.0391 & 3.184E-28 & CRDS & 8130.039100 & $3.450 \mathrm{E}-28$ & 8130.0104514772 & 2.43E-04 & $3.411 \mathrm{E}-28$ & 8130.03640 & 107 \\
\hline 041 & 6 & 3 & 3 & 010 & 7 & 3 & 4 & 8171.1013 & $2.893 \mathrm{E}-27$ & CRDS & 8171.101300 & $3.030 \mathrm{E}-27$ & 8171.1068258698 & 5.34E-04 & $3.180 \mathrm{E}-27$ & 8171.10028 & 12 \\
\hline 041 & 4 & 1 & 4 & 010 & 4 & 1 & 3 & 8194.9260 & $1.058 \mathrm{E}-27$ & CRDS & 8194.926000 & $9.990 \mathrm{E}-28$ & 8194.9309331881 & $5.10 \mathrm{E}-04$ & $1.171 \mathrm{E}-27$ & 8194.92556 & 11 \\
\hline 031 & 11 & 4 & 8 & 000 & 11 & 6 & 5 & 8212.4782 & $1.919 \mathrm{E}-28$ & FTS & 8212.478200 & $1.930 \mathrm{E}-28$ & 8212.4858878476 & $5.07 \mathrm{E}-04$ & $2.033 \mathrm{E}-28$ & 8212.47781 & 16 \\
\hline 041 & 2 & 2 & 1 & 010 & 3 & 2 & 2 & 8225.6318 & $5.538 \mathrm{E}-27$ & FTS & 8225.631800 & $5.590 \mathrm{E}-27$ & 8225.6273492445 & $5.07 \mathrm{E}-04$ & $6.120 \mathrm{E}-27$ & 8225.63099 & 7 \\
\hline 050 & 8 & 4 & 5 & 000 & 8 & 1 & 8 & 8373.1227 & 7.577E-27 & FC-CRDS & 8373.122490 & $8.413 \mathrm{E}-27$ & 8373.1154645483 & $2.52 \mathrm{E}-04$ & $8.682 \mathrm{E}-27$ & 8373.12285 & 29 \\
\hline 031 & 10 & 6 & 5 & 000 & 11 & 6 & 6 & 8374.7169 & $7.311 \mathrm{E}-27$ & CRDS & 8374.716409 & $7.465 \mathrm{E}-27$ & 8374.7109784661 & $3.10 \mathrm{E}-04$ & 7.734E-27 & 8374.71792 & 22 \\
\hline 130 & 10 & 6 & 4 & 000 & 10 & 7 & 3 & 8404.0919 & $2.504 \mathrm{E}-29$ & estimated & 8404.350500 & $2.652 \mathrm{E}-29$ & 8404.0596599018 & $-1.00 \mathrm{E}+00$ & $4.218 \mathrm{E}-29$ & 8404.09726 & \\
\hline 050 & 11 & 5 & 6 & 000 & 11 & 2 & 9 & 8444.3589 & 2.727E-27 & CRDS & 8444.346869 & $3.047 \mathrm{E}-27$ & 8444.3472713304 & $1.83 \mathrm{E}-04$ & $3.206 \mathrm{E}-27$ & 8444.35805 & 59 \\
\hline 130 & 10 & 6 & 4 & 000 & 11 & 5 & 7 & 8472.6758 & $1.111 \mathrm{E}-27$ & estimated & & & 8472.6434325378 & $-1.00 \mathrm{E}+00$ & $1.179 \mathrm{E}-27$ & 8472.68042 & \\
\hline 050 & 9 & 6 & 4 & 000 & 9 & 5 & 5 & 8486.8443 & $1.296 \mathrm{E}-27$ & CRDS & 8486.843174 & $1.424 \mathrm{E}-27$ & 8486.8495531909 & $1.09 \mathrm{E}-03$ & $1.457 \mathrm{E}-27$ & 8486.84099 & 8 \\
\hline 141 & 9 & 0 & 9 & 000 & 10 & 0 & 10 & & & & 13032.507075 & $1.996 \mathrm{E}-28$ & 13032.5041108916 & $1.69 \mathrm{E}-02$ & $1.600 \mathrm{E}-28$ & 13032.53359 & 2 \\
\hline 240 & 8 & 2 & 7 & 000 & 9 & 1 & 8 & & & & 13065.552492 & $9.740 \mathrm{E}-29$ & 13065.5518211326 & $1.85 \mathrm{E}-03$ & $6.057 \mathrm{E}-29$ & 13065.57542 & 13 \\
\hline 090 & 4 & 1 & 4 & 000 & 3 & 0 & 3 & & & & 13098.217056 & $9.030 \mathrm{E}-29$ & 13098.0051902323 & $1.18 \mathrm{e}-03$ & $1.162 \mathrm{E}-28$ & 13098.25826 & 214 \\
\hline 240 & 6 & 0 & 6 & 000 & 6 & 1 & 5 & & & & 13099.021474 & $8.751 \mathrm{E}-28$ & 13099.0208384440 & $1.00 \mathrm{E}-02$ & $1.209 \mathrm{E}-27$ & 13098.95766 & 6 \\
\hline 141 & 7 & 1 & 6 & 000 & 8 & 1 & 7 & & & & 13108.642694 & $3.769 \mathrm{E}-28$ & 13108.6414279826 & $1.94 \mathrm{E}-02$ & 3.017E-28 & 13108.56996 & 4 \\
\hline 240 & 1 & 1 & 1 & 000 & 0 & 0 & 0 & & & & 13262.564410 & $2.007 \mathrm{E}-27$ & 13262.5644083504 & $9.62 \mathrm{E}-03$ & $3.066 \mathrm{E}-27$ & 13262.59066 & 3 \\
\hline
\end{tabular}


Notes.

${ }^{a}$ The MC2020 positions and intensities were reported in Ref. [27] for the $5690-8340 \mathrm{~cm}^{-1}$ and are presently calculated from known empirical energy values for the lines in the $8120-8230 \mathrm{~cm}^{-1}$ interval.

${ }^{b}$ Intensity values derived from the results of Schwenke and Partridge (SP) [49-51]

${ }^{c}$ Experimental origin of the upper energy value used to compute the MC2020 positions: FTS, CRDS or FC-CRDS (labeled CA-CRDS in Ref. [27]).

${ }^{d} R=\frac{\mid \text { Meas. }-W 2020 \mid}{\text { UncW2020 }}$ is the ratio of the absolute deviation of the W2020 position from the CRDS position value measured in this work by the W2020 wavenumber uncertainty. 


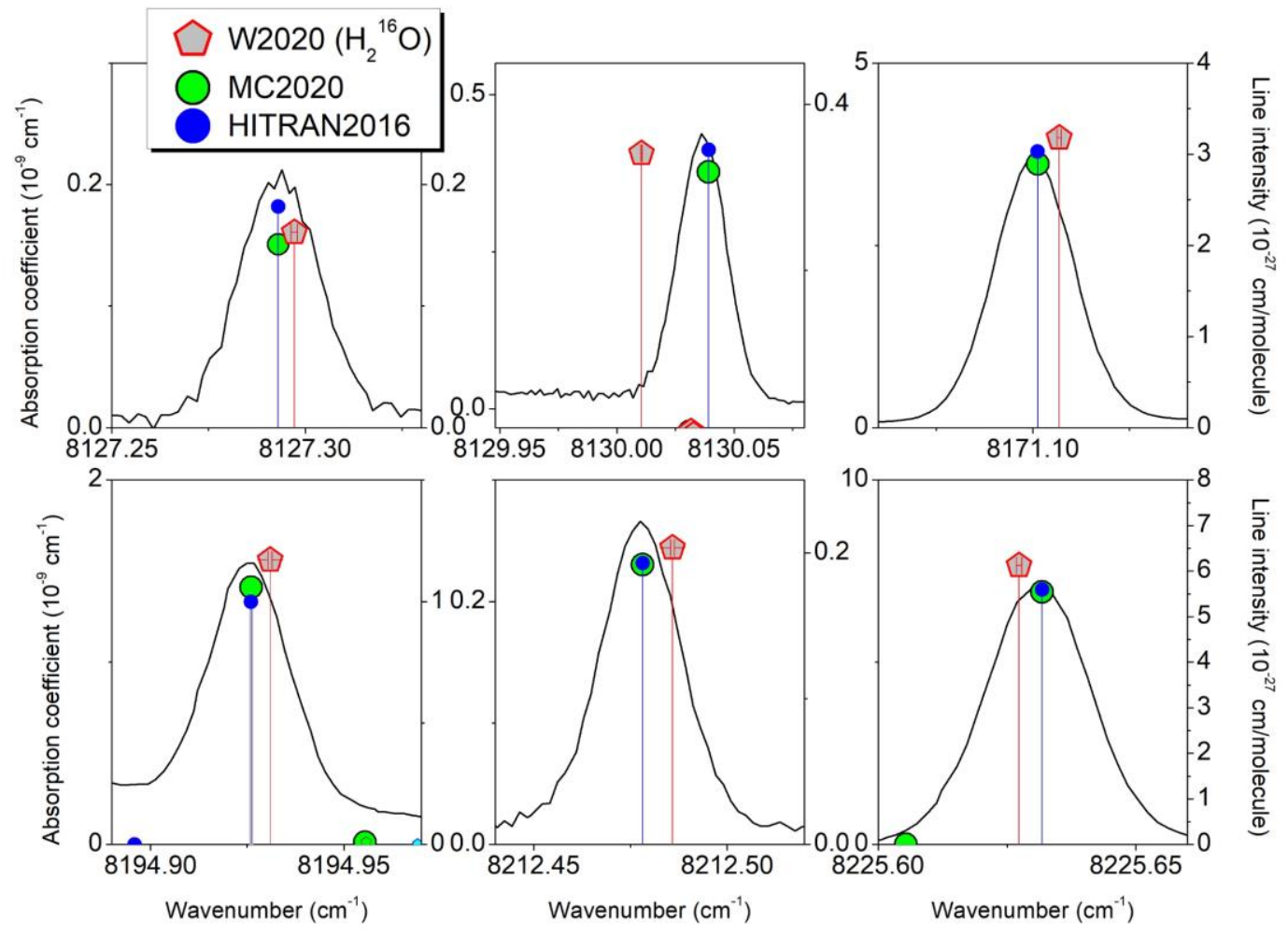

\section{Fig. 2}

Same as Fig. 1 in the $8120-8230 \mathrm{~cm}^{-1}$ region.

As a distinct validation test, the newly recorded FC-CRDS was considered above $8340 \mathrm{~cm}^{-1}$, thus in a region for which no CRDS study was previously reported. The energy levels derived from the same sources as considered for MC2020 [27] were used to generate a line list in the $8340-8600 \mathrm{~cm}^{-1}$ interval on the basis of SP variational line lists [49-51]. As illustrated in Fig. 3, the comparison with the W2020 list shows similar situations than below $8340 \mathrm{~cm}^{-1}$, the MC2020 positions being in better agreement with the observations than the W2020 values. It indicates that position values available in the literature (and thus included in the W2020 transition database) can provide energy levels more accurately than the W2020 values. Let us note that the W2020 list includes some positions with large error bars corresponding to unknown upper energy values for which a variational value was adopted. Two such examples are displayed in Fig. 3: the transitions at 8404.059 and $8472.643 \mathrm{~cm}^{-1}$ are provided with an artificial $-1 \mathrm{~cm}^{-1}$ error bar. Both transitions are provided without complete vibration-rotation assignment in the W2020 list while they should be assigned to (130) $10_{64-(000)} 10_{73}$ and (130) $10_{64-(000)} 11$ 57 transitions, respectively (we use the $\left(V_{1} V_{2} V_{3}\right) J_{K a} K c$ notation for the vibration-rotation energy levels). In agreement with the W2020 transition database, we confirm that the (130) $10_{64}$ upper level (which is common to the two transitions) was not yet determined correctly. It can nevertheless be estimated reasonably by extrapolation from nearby rovibrational levels as was done in Ref. [27]. For the four other 
examples displayed in Fig. 3, the needed upper energy level was obtained from the CRDS studies [16$18,20,25]$. The three strongest problematic lines at $8373.1227,8374.7169$, and $8444.3589 \mathrm{~cm}^{-1}$ were also measured from FTS spectra recorded in Reims [32]. The FTS line positions, marked with a yellow star on Fig. 3, agree with the MC2020 values. These are clear examples when the xMARVEL code considered the coinciding CRDS and FTS data but converges to a different position, possibly due to the improper treatment of inaccurate sources impacting the resulting value and/or biases in the procedure.

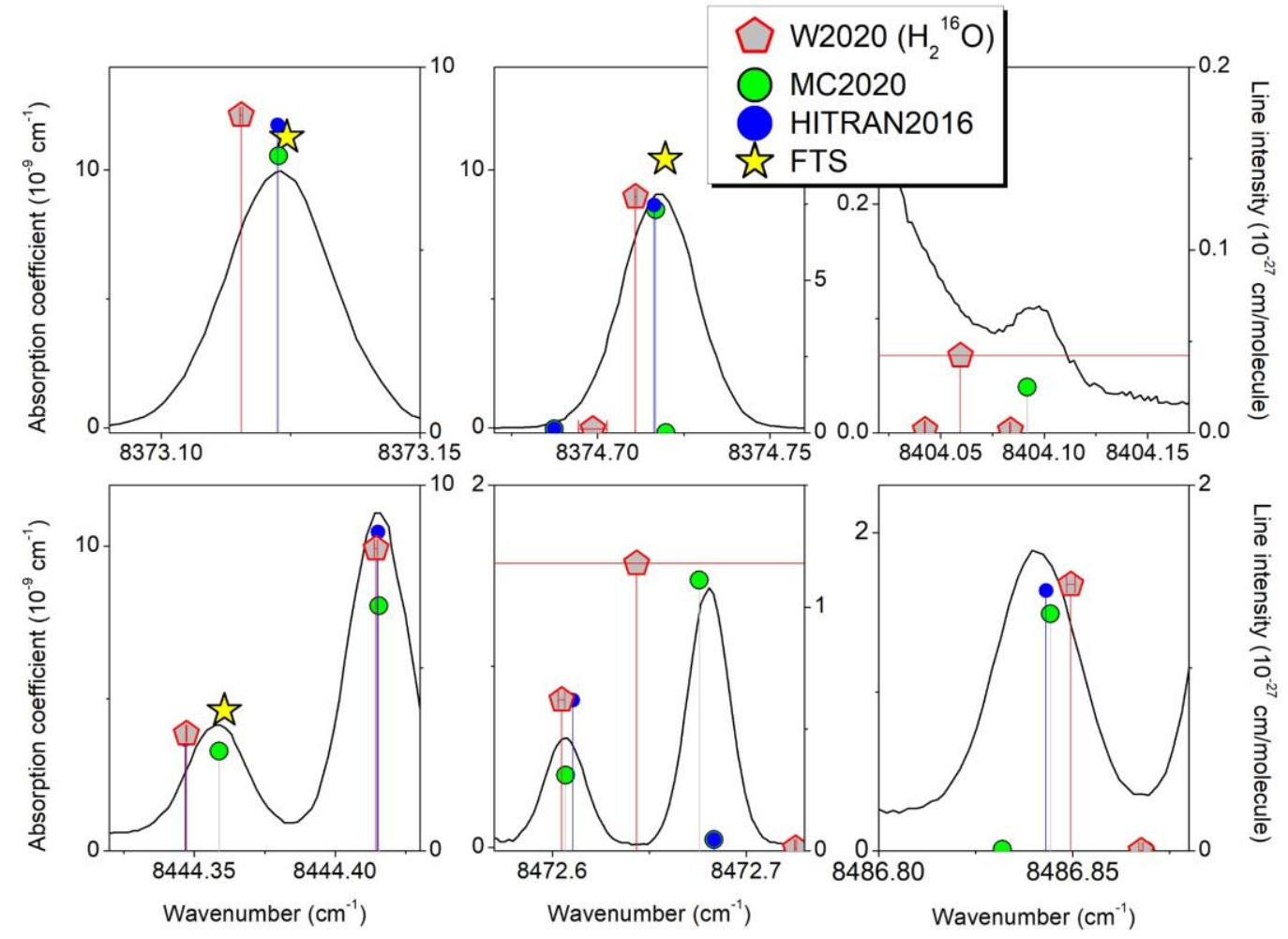

Fig. 3

Same as Fig. 1 in the region above $8340 \mathrm{~cm}^{-1}$ which is newly recorded by CRDS. Among the six problematic lines, the three strongest ones (at 8373.1227, 8374.7169 and $8444.3589 \mathrm{~cm}^{-1}$ ) were measured by FTS in Ref. [32]. The corresponding FTS positions are indicated with yellow stars. The two W2020 line positions with very large error bar (at 8404.0596 and $8486.8496 \mathrm{~cm}^{-1}$ ) reach the same (130) 1064 upper level. The energy of this upper level is unknown in the literature.

As mentioned above, the systematic line list retrieval and assignment of the new FC-CRDS spectra are displayed in Figs. 1-3 will be reported elsewhere. For the purpose of the present comparison, we have derived the line centers of the 18 problematic lines listed in Table 1. The obtained values have been used in Fig. 4 for a comparison with W2020 and MC2020. The overview comparison of the line positions confirms the conclusions drawn from the direct comparison to the spectrum. We have included in the last column of Table 1, the ratio $R=\frac{\mid \text { Meas. }-W 2020 \mid}{U n c W 2020}$ corresponding to the absolute deviation of the 
W2020 position from the CRDS position value measured in this work by the W2020 wavenumber uncertainty. For the transitions displayed in Figs. 1-3, $R$ values range between 3 and 107.

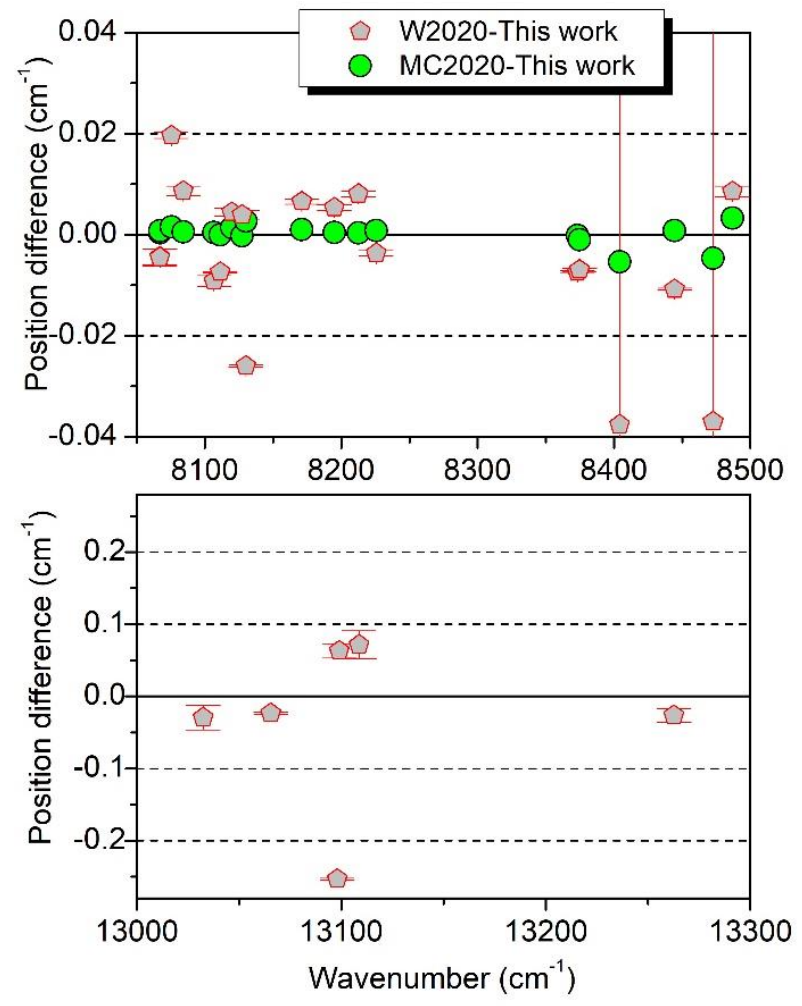

\section{Fig. 4}

Upper panel: Differences between the W2020 (MC2020) positions and the values presently derived from the new FC-CRDS spectrum in the $8100-8600 \mathrm{~cm}^{-1}$ region (grey pentagons and green circles, respectively). The W2020 error bars are displayed (the two very large values correspond to the (130) 10 64 transitions reaching the (130) 1064 upper level which is experimentally unknown - see Text). The error bar on the MC2020 positions below $8340 \mathrm{~cm}^{-1}$ is $10^{-3} \mathrm{~cm}^{-1}$ [27].

Lower panel: Differences between the W2020 positions and the values presently derived from the new CRDS spectrum in the $13000-13300 \mathrm{~cm}^{-1}$ region. Note the change of the ordinate scale.

\subsection{Systematic comparison of the W2020 and MC2020 positions in the $5690-8340 \mathrm{~cm}^{-1}$ region}

The first step of a systematic comparison between the W2020 and MC2020 positions of $\mathrm{H}_{2}{ }^{16} \mathrm{O}$ is to associate transitions of the two lists. The rovibrational assignment was the first criterion. All the MC2020 transitions are provided with a unique assignment, but a significant number of the W2020 transitions have an upper level without vibrational labeling and $K a K c$ values (only the $J$ value is given). In those cases, W2020 and MC2020 transitions were associated when they have identical lower state and upper $J$ value and their positions and intensities are close (within $0.1 \mathrm{~cm}^{-1}$ and $15-20 \%$, respectively). (Note that $420 \mathrm{~W} 2020$ assignments differ from those in MC2020). In order to be consistent with the W2020 approach, we limit the comparison to transitions with MC2020 positions calculated from accurate upper energy levels determined by FTS, CRDS, FC-CRDS or Lamb dip, and thus excluded those with estimated or with variational origins (see Table 2 of Ref. [27]). The MC2020 uncertainty of the compared line positions is thus believed to be better than $10^{-3} \mathrm{~cm}^{-1}$. The comparison 
file is provided as Supplementary Material. The corresponding histogram of the position differences is presented in Fig. 5. Of a total of more than 25,000 line positions, $69 \%$ W2020 and MC2020 values coincide within the $10^{-3} \mathrm{~cm}^{-1} \mathrm{MC} 2020$ uncertainty. It leaves about 8000 positions showing larger deviations which are thus believed to be less accurate in the W2020 list.

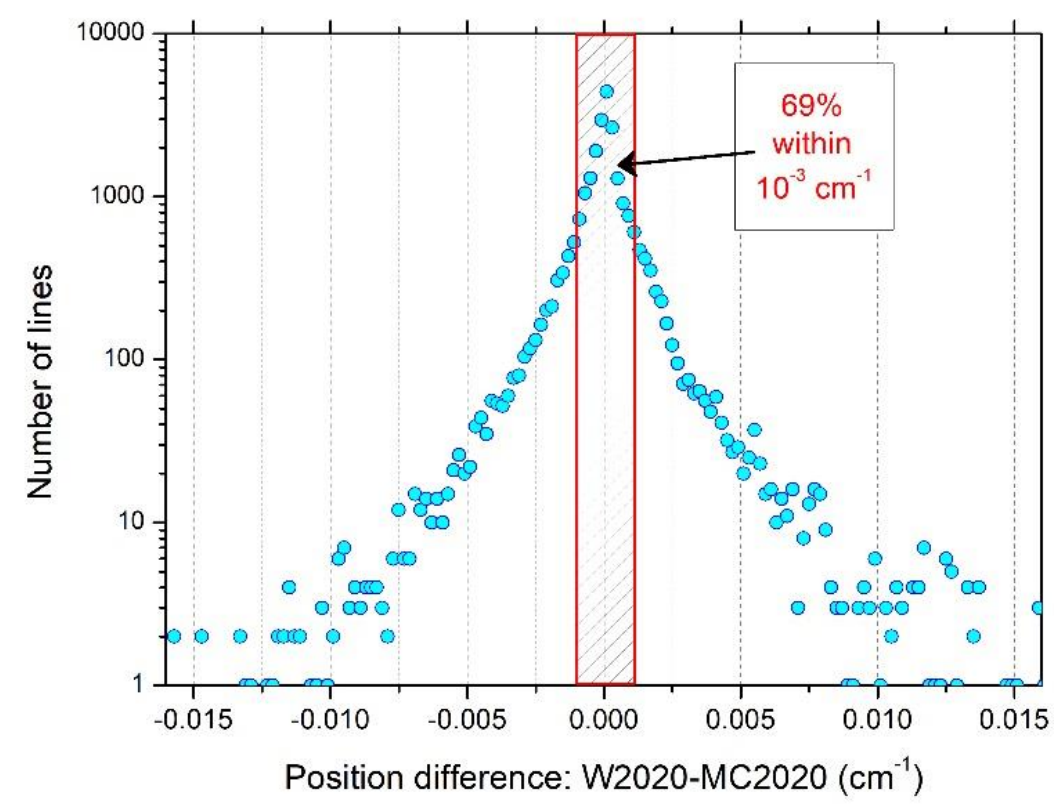

\section{Fig. 5}

Differences between the W2020 and MC2020 line positions of $\mathrm{H}_{2}{ }^{16} \mathrm{O}$ in the $5690-8340 \mathrm{~cm}^{-1}$ region. The histogram presents the number of lines versus the deviation value $\left(2 \times 10^{-4} \mathrm{~cm}^{-1}\right.$ step). About $69 \%$ of the W2020 and MC2020 values coincide within the $10^{-3} \mathrm{~cm}^{-1}$ estimated uncertainty of the MC2020 values.

\section{Region $13000-13300 \mathrm{~cm}^{-1}$}

In order to consider to what extent the inaccuracies of the W2020 list evidenced in the 8000 $8600 \mathrm{~cm}^{-1}$ region are present in other spectral regions, we present here validation tests in the 13000 $13300 \mathrm{~cm}^{-1}$ region, on the basis of CRDS spectral newly recorded at the Institute of Atmospheric Optics, Tomsk. A separate publication will be devoted to the presentation of the setup and the systematic analysis of the spectra. Briefly, an ECDL (Sacher Lasertechnik TEC-500-0770-030) was used as a light source, and the room temperature recordings were performed at two pressures around 9 and 19 Torr. The noise equivalent absorption evaluated as the rms of the baseline fluctuations is around $5 \times 10^{-11}$ $\mathrm{cm}^{-1}$. The recorded spectra cover the entire range of the A band of oxygen near $760 \mathrm{~nm}$, largely used by different space missions, for air-mass determination. Although being a transparency window for water vapor (maximum line intensities are on the order of $10^{-26} \mathrm{~cm} /$ molecule), it is important to quantify to what extent the $\mathrm{O}_{2}$ retrieval is affected by water interfering lines. Accurate values of the line positions of $\mathrm{O}_{2}$ (present as an impurity in the water vapor sample) were used to calibrate the spectra: twenty-seven $\mathrm{O}_{2}$ positions sampling the $13020-13170 \mathrm{~cm}^{-1}$ interval were used to adjust the frequency axis, leading to an $r m s$ of $1.1 \times 10^{-4} \mathrm{~cm}^{-1}$ for the (meas. - HITRAN2016) position differences. 
It is worth underlining that the quality of the water vapor line lists in this region is not at the level achieved in the $8000 \mathrm{~cm}^{-1}$ range both for line positions and line intensities. As intensity measurements are mostly absent, spectroscopic databases as HITRAN2016 adopted line intensities computed variationally using an $a b$ initio dipole moment surface. The comparison with the present measured CRDS values shows frequent discrepancies by factors larger than 2 , and a large dispersion is observed between the SP [49-51], BT2 [53] and PoKaZaTeL [48] calculated values. The intensity retrieval and comparison to calculated values will be included in the above-mentioned future publication.

As concerns line positions, many of the observed transitions are newly detected and part of them reach energy levels that were not yet determined experimentally. The known energy levels rely on the most sensitive previous work in the region, performed by ICLAS [54], and on measurements performed in different spectral regions. As no recent measurements were published in the region, the IUPAC-TG [8] and W2020 energy levels are close. Note that HITRAN2016 line positions in the region mostly rely on the IUPAC-TG line positions [8].

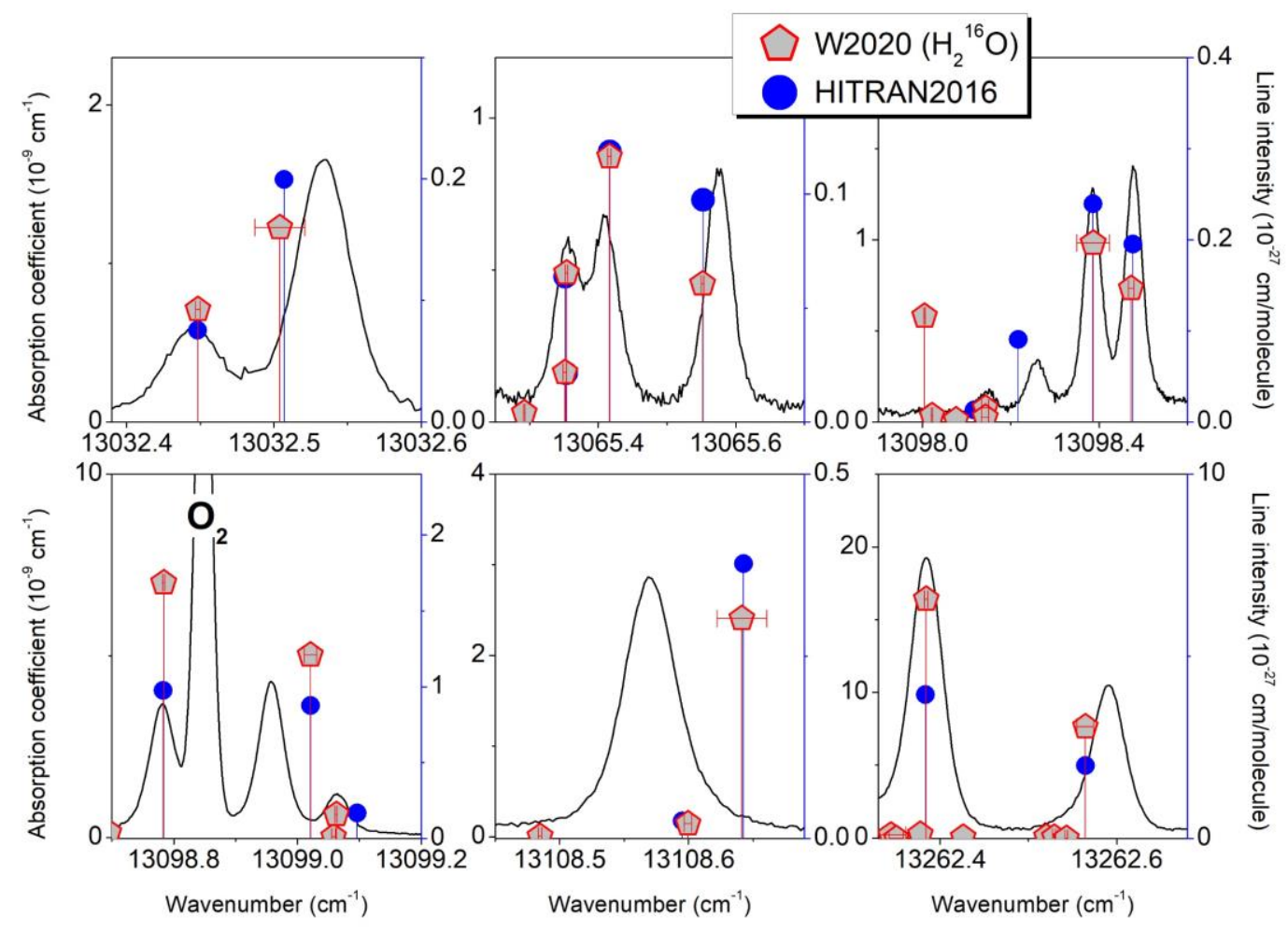

\section{Fig. 6}

Examples of discrepancies between the CRDS spectrum of water vapor recorded at 9.00 Torr and the W2020 line list of $\mathrm{H}_{2}{ }^{16} \mathrm{O}$ (grey pentagons). The HITRAN2016 [47] list of natural water is plotted for comparison (blue circles). Note the important differences between the (variational) line intensities included in W2020 and HITRAN2016 lists (from PoKaZaTeL [49] and BT2 [53] origin, respectively). 
In Fig. 6, the CRDS spectrum is superimposed to the stick spectra corresponding to the W2020 list of $\mathrm{H}_{2}{ }^{16} \mathrm{O}$ and to the HITRAN2016 list of natural water. Large variations between the W2020 and HITRAN2016 line intensities are noted, both showing deviations from the measurements (see values included in Table 1). In the same way as in the previous region, part of the W2020 line positions deviate significantly from the observations. As illustrated in Fig. 4 (lower panel), the W2020 claimed error bars appear to be considerably underestimated in some cases. The corresponding deviations exceed the W2020 uncertainty by values ranging between 2 and 214 (see $R$ values in Table 1)

\section{Concluding remarks}

The elaboration of the most accurate set of rovibrational energy levels of water vapor (and other major atmospheric species) is of importance for the spectroscopic community. In principle, the accuracy of the derived energy values should benefit from all the measurements of transition frequencies available in the literature. The laudable objective to be exhaustive has led the authors of the IUPAC-TG and W2020 energy levels to collect a large variety of measurements in a single transition database for each water isotopologue. In the case of $\mathrm{H}_{2}{ }^{16} \mathrm{O}$, the W2020 transition database gathers about 300,000 transition frequencies of about 200 literature sources [10,11]. The accuracy of the collected transition frequencies spans over seven orders of magnitude (see Table 1 of Ref. [10]). The MARVEL and xMARVEL procedures have been developed to treat this large amount of data in a consistent way, but this task is made very challenging not only due to the variety and amount of data but also because $(i)$ spectral calibration of some spectra is not accurate, (ii) reliable experimental uncertainties are generally unreported in the original sources, (iii) rovibrational assignments are not always consistent and (iv) part of the reported line positions are assigned to several transitions, in particular in emission spectra $(v)$ some references include artifacts, spurious lines or even impurity lines assigned to water vapor transitions. As a result, due to conflictive measurements, a number of inaccurate IUPAC-TG energy levels were obtained because the MARVEL procedure inadvertently privileged less accurate data and excluded accurate measurements (see detailed discussion and examples in Refs. [18-20]). The difficulty in consistently treating the whole transition dataset led to some misleading statements on the accuracy of some experimental sources: in Ref. [12], Tobias et al. excluded the FTS study of Ref. [32] and the FC-CRDS works of Refs. $[25,26]$ claiming that they "are not sufficiently accurate for the purposes of the present study" while these studies are among the most relevant and accurate in the near-infrared (They are now included in the W2020 transition database [10]).

All these difficulties resulted in increased complexity and sophistication in the new MARVEL procedure (see Fig. 1 of Ref. [10]), which, in our opinion, makes it necessary to carry out validation tests at the end of the process. As an increased accuracy is expected from the global treatment of all literature sources, Furtenbacher and coworkers recommended the W2020 transition frequencies for spectroscopic databases as HITRAN [12]. The validation tests presented above in two distinct spectral regions do not support this recommendation. By contrast, the comparison to CRDS spectra referenced 
to a frequency comb near $8400 \mathrm{~cm}^{-1}$ indicates that more accurate transition frequencies can be obtained using a limited number of high-quality experimental sources (about 30 compared to 200 for the MC2020 [27] and W2020 [11] line lists, respectively). The MC2020 line positions in the $5690-8340 \mathrm{~cm}^{-1}$ region rely on absorption measurements, all published and included in the W2020 transition databases. We thus conclude that in many cases, the W2020 positions are affected by other (less accurate) experimental sources or/and that the xMARVEL treatment is not optimum.

In our opinion, some issues are related to the choice of treating the sources in a similar way and not favoring recent sources against elder ones, absorption data against emission data. This option misses the progress and improvements with time. There are different groups who have successively published several analyses of water spectra in the same region and their most recent line list is expected to supersede the previous ones by correcting assignment errors, improving the line position accuracy, etc. Treating equivalently the different iterations leads to intermediate values which are worse than those of the most recent publication. As an example, in our current analysis of the water spectrum in the oxygen A-band region, we discovered that a few W2020 energy levels rely on (or are impacted by) line positions of the A band of oxygen which were erroneously assigned to water transitions in the FTS spectra of Ref. [55]. These erroneous lines were removed in the updated analysis of the same FTS spectra [56] but part of the $\mathrm{O}_{2}$ line positions of Ref. [55] are included in the W2020 transition database [11].

The series of examples presented in Figs. 1-3 and $\mathbf{6}$ have also illustrated the fact that the wavenumber uncertainty attached to the W2020 positions can be considerably underestimated (by a factor up to 200 - see Table 1) and should be used with caution. The systematic comparison of the MC2020 and W2020 lists of $\mathrm{H}_{2}{ }^{16} \mathrm{O}$ in the $5690-8340 \mathrm{~cm}^{-1}$ region (about 25,000 line positions) suggests that the accuracy of more than one-third of the W2020 positions in the region can be improved using data available in the literature.

The global inversion of transition frequencies to derive energy levels is particularly complex in the case of $\mathrm{H}_{2}{ }^{16} \mathrm{O}$. Let us underline that having at disposal high-quality spectra for direct comparison to the generated line list is a crucial advantage, in particular in cases of discrepancies between different sources. Figure 1 in the HITRAN2012 paper [55] proposes an overview of an "ideal" process of compiling a database from multiple and diverse sources. Validation of the parameters against laboratory and field (atmospheric) data is an integral part of the process. We recommend that a similar procedure should be a part of the MARVEL database as well, prior to the official release or making definitive statements on the relative quality of the input experimental data. Although we did not perform a systematic comparison of the W2020 positions of $\mathrm{H}_{2}{ }^{17} \mathrm{O}$ and $\mathrm{H}_{2}{ }^{18} \mathrm{O}$ [11] to our CRDS spectra recorded with isotopically enriched samples [22, 24-26], some examples suggest that the W2020 line lists of $\mathrm{H}_{2}{ }^{17} \mathrm{O}$ and $\mathrm{H}_{2}{ }^{18} \mathrm{O}$ show deficiencies similar to those of the main isotopologue.

The correction of the transition frequencies of theoretical line lists, using empirical energy levels provided by the MARVEL procedure has proven to be highly valuable not only in the case of water 
isotopologues but also for other molecules such as $\mathrm{S}^{16} \mathrm{O}_{2}$ [57], $\mathrm{C}_{2} \mathrm{H}_{2}$ [58], $\mathrm{H}_{2} \mathrm{~S}$ [59], $\mathrm{NH}_{3}$ [60], or formaldehyde [61]. The lower state energy combination relations allow for propagating experimental accuracy of measured transitions to not yet observed transitions located in distinct spectral regions. The above difficulties related to the amount of data to be treated in the case of water isotopologues are significantly reduced for the above molecules, for which the number of sources is more limited. Nevertheless, going back to spectra as presented above for water vapor appears to be a necessary step to close the loop and ensure the quality of the released positions and associated error bars.

\section{Acknowledgements}

The support of the CNRS (France) in the frame of International Research Project SAMIA is acknowledged. SNM activity was also partly supported in the frame of the Russian Science Foundation, grant no. 18-11-00024-П. CRDS measurements near $760 \mathrm{~nm}$ were performed at IAO-Tomsk and funded by RFBR project 20-32-70054. 
1. Jastrow R. On the Rydberg-Ritz formula in quantum mechanics. Phys Rev 1948;73:60-7. https://doi.org/10.1103/PhysRev.73.60.

2. Flaud J-M, Camy-Peyret C, Maillard JP. Higher ro-vibrational levels of $\mathrm{H}_{2} \mathrm{O}$ deduced from high resolution oxygen-hydrogen flame spectra between $2800-6200 \mathrm{~cm}^{-1}$. Mol Phys 1976;32 499-521. https://doi.org/10.1080/00268977600103251.

3. Tashkun SA, Perevalov VI, Teffo J-L, Bykov AD, Lavrentieva NN. CDSD-1000, the hightemperature carbon dioxide spectroscopic databank. J Quant Spectrosc Radiat Transfer 2003;82:165-96. https://doi.org/10.1016/S0022-4073(03)00152-3.

4. Furtenbacher T, Császár AG, Tennyson J. MARVEL: measured active rotational-vibrational energy levels. J Mol Spectrosc 2007;245:115-25. https://doi.org/10.1016/j.jms.2007.07.005.

5. Furtenbacher T, Császár AG. MARVEL: measured active rotational-vibrational energy levels. II. Algorithmic improvements. J Quant Spectrosc Radiat Transfer 2012;113:929-35. https://doi.org/10.1016/j.jqsrt.2012.01.005.

6. Tennyson J, Bernath PF, Brown LR, Campargue A, Carleer MR, Császár AG, et al. IUPAC critical evaluation of the rotational-vibrational spectra of water vapor. Part I. Energy levels and transition wavenumbers for $\mathrm{H}_{2}{ }^{17} \mathrm{O}$ and $\mathrm{H}_{2}{ }^{18} \mathrm{O}$. J Quant Spectrosc Radiat Transfer 2009;110:573-96. https://doi.org/10.1016/j.jqsrt.2009.02.014.

7. Tennyson J, Bernath PF, Brown LR, Campargue A, Császár AG, Daumont L, et al. IUPAC critical evaluation of the rotational-vibrational spectra of water vapor. Part II. Energy levels and transition wavenumbers for $\mathrm{HD}^{16} \mathrm{O}, \mathrm{HD}^{17} \mathrm{O}$, and $\mathrm{HD}^{18} \mathrm{O}$. J Quant Spectrosc Radiat Transfer 2010;111:216084. https://doi.org/10.1016/j.jqsrt.2010.06.012.

8. Tennyson J, Bernath PF, Brown LR, Campargue A, Császár AG, Daumont L, et al. IUPAC critical evaluation of the rotational-vibrational spectra of water vapor. Part III: Energy levels and transition wavenumbers for $\mathrm{H}_{2}{ }^{16} \mathrm{O}$. J Quant Spectrosc Radiat Transfer 2013;117;29-58. https://doi.org/10.1016/j.jqsrt.2012.10.002.

9. Tennyson J, Bernath PF, Brown LR, Campargue A, Császár AG, Daumont L, et al. IUPAC critical evaluation of the rotational-vibrational spectra of water vapor. Part IV. Energy levels and transition wavenumbers for $\mathrm{D}_{2}{ }^{16} \mathrm{O}, \mathrm{D}_{2}{ }^{17} \mathrm{O}$, and $\mathrm{D}_{2}{ }^{18} \mathrm{O}$. J Quant Spectrosc Radiat Transfer 2014;142:93-108. https://doi.org/10.1016/j.jqsrt.2014.03.019.

10. Furtenbacher T, Tobias R, Tennyson J, Polyansky OL, Császár AG. W2020: A database of validated rovibrational experimental transitions and empirical energy levels of $\mathrm{H}_{2}{ }^{16} \mathrm{O}$. J Phys Chem Ref Data 2020;49:033101. https://doi.org/10.1063/5.0008253.

11. Furtenbacher T, Tobias R, Tennyson J, Polyansky OL, Kyuberis AA, Ovsyannikov RI, et al. The W2020 database of validated rovibrational experimental transitions and empirical energy levels of water isotopologues. II. $\mathrm{H}_{2}{ }^{17} \mathrm{O}$ and $\mathrm{H}_{2}{ }^{18} \mathrm{O}$ with an update to $\mathrm{H}_{2}{ }^{16} \mathrm{O}$. J Phys Chem Ref Data 2020;49:043103. https://doi.org/10.1063/5.0030680.

12. Tobias R, Furtenbacher T, Tennyson J, Császár AG. Accurate empirical rovibrational energies and transitions of $\mathrm{H}_{2}{ }^{16} \mathrm{O}$. Phys Chem Chem Phys 2019;21:3473-95. https://doi.org/10.1039/C8CP05169K.

13. Tobias R, Furtenbacher T, Császár AG. Cycle bases to the rescue J. Quant. Spectrosc. Radiat. Transfer 2017; 203, 557-64. https://doi.org/10.1016/j.jqsrt.2017.03.031

14. Macko P, Romanini D, Mikhailenko SN, Naumenko OV, Kassi S, Jenouvrier A et al. High sensitivity CW-cavity ring down spectroscopy of water in the region of the $1.5 \mu \mathrm{m}$ atmospheric window. J Mol Spectrosc 2004;227:90-108. https://doi.org/10.1016/j.jms.2004.05.020.

15. Mikhailenko SN, Wang L, Kassi S, Campargue A. Weak water absorption lines around 1.455 and $1.66 \mu \mathrm{m}$ by CW-CRDS. J Mol Spectrosc 2007;244:170-8. https://doi.org/10.1016/j.jms.2007.05.013.

16. Mikhailenko S, Kassi S, Wang L, Campargue A. The absorption spectrum of water in the $1.25 \mu \mathrm{m}$ transparency window $\left(7408-7920 \mathrm{~cm}^{-1}\right)$. J Mol Spectrosc 2011;269:92-103. https://doi.org/10.1016/j.jms.2011.05.005. 
17. Leshchishina O, Mikhailenko S, Mondelain D, Kassi S, Campargue A. CRDS of water vapor at 0.1 Torr between 6886 and $7406 \mathrm{~cm}^{-1}$. J Quant Spectrosc Radiat Transfer 2012;113:2155-66. https://doi.org/10.1016/j.jqsrt.2012.06.026.

18. Leshchishina O, Mikhailenko S, Mondelain D, Kassi S, Campargue A. An improved line list for water vapor in the $1.5 \mu \mathrm{m}$ transparency window by highly sensitive CRDS between 5852 and 6607 $\mathrm{cm}^{-1}$. J Quant Spectrosc Radiat Transfer 2013;130:69-80. https://doi.org/10.1016/j.jqsrt.2013.04.010.

19. Mikhailenko SN, Karlovets EV, Vasilchenko S, Mondelain D, Kassi S, Campargue A. New transitions and energy levels of water vapor by high sensitivity CRDS near 1.73 and $1.54 \mu \mathrm{m}$. J Quant Spectrosc Radiat Transfer 2019;236;106574. https://doi.org/10.1016/j.jqsrt.2019.106574.

20. Campargue A, Mikhailenko SN, Lohan BG, Karlovets EV, Mondelain D, Kassi S. The absorption spectrum of water vapor in the $1.25 \mu \mathrm{m}$ atmospheric window $\left(7911-8337 \mathrm{~cm}^{-1}\right)$. J Quant Spectrosc Radiat Transfer 2015;157:135-52. https://doi.org/10.1016/j.jqsrt.2015.02.011.

21. Liu A-W, Naumenko OV, Kassi S, Campargue A. CW-Cavity Ring Down Spectroscopy of deuterated water in the $1.58 \mu \mathrm{m}$ atmospheric transparency window. J Quant Spectrosc Radiat Transfer 2014;138:97-106. https://doi.org/10.1016/j.jqsrt.2014.02.002.

22. Liu A, Naumenko O, Kassi S, Campargue A. High sensitivity CW-CDRS of ${ }^{18} \mathrm{O}$ enriched water near $1.6 \quad \mu \mathrm{m}$. J Quant Spectrosc Radiat Transfer 2009;110:1781-800. https://doi.org/10.1016/j.jqsrt.2009.04.013.

23. Mikhailenko SN, Mondelain D, Karlovets EV, Kassi S, Campargue A. Cavity ring down spectroscopy of ${ }^{17} \mathrm{O}$ enriched water vapor near $1.73 \mu \mathrm{m}$. J Quant Spectrosc Radiat Transfer 2019;222-223:229-35. https://doi.org/10.1016/j.jqsrt.2018.10.027.

24. Mikhailenko SN, Leshchishina O, Karlovets EV, Mondelain D, Kassi S, Campargue A. CRDS of ${ }^{17} \mathrm{O}$ enriched waterbetween 5850 and $6671 \mathrm{~cm}^{-1}$ : more than 1000 energy levels of $\mathrm{H}_{2}{ }^{17} \mathrm{O}$ and $\mathrm{HD}^{17} \mathrm{O}$ newly determined. J Quant Spectrosc Radiat Transfer. 2016;177;108-16. https://doi.org/10.1016/j.jqsrt.2015.11.016.

25. Mondelain D, Mikhailenko SN, Karlovets EV, Béguier S, Kassi S, Campargue A. Comb-assisted cavity ring down spectroscopy of ${ }^{17} \mathrm{O}$ enriched water between 7443 and $7921 \mathrm{~cm}^{-1}$. J Quant Spectrosc Radiat Transfer 2017;203;206-12. https://doi.org/10.1016/j.jqsrt.2017.03.029.

26. Mikhailenko SN, Mondelain D, Karlovets EV, Kassi S, Campargue A. Comb-assisted cavity ring down spectroscopy of ${ }^{17} \mathrm{O}$ enriched waterbetween 6667 and $7443 \mathrm{~cm}^{-1}$. J Quant Spectrosc Radiat Transfer 2018;206:163-71. https://doi.org/10.1016/j.jqsrt.2017.10.023.

27. Mikhailenko S, Kassi S, Mondelain D, Campargue A. Water vapor absorption between 5690 and $8340 \mathrm{~cm}^{-1}$ : Accurate empirical line centers and validation tests of calculated line intensities. J Quant Spectrosc Radiat Transfer 2020;245:106840. https://doi.org/10.1016/j.jqsrt.2020.106840.

28. Lisak D, Havey DK, Hodges JT. Spectroscopic line parameters of water vapor for rotation-vibration transitions near $7180 \mathrm{~cm}^{-1}$. Phys Rev A 2009;79:052507. https://doi.org/10.1103/PhysRevA.79.052507.

29. Sironneau VT, Hodges JT. Line shapes, positions and intensities of water transitions near $1.28 \mu \mathrm{m}$. J Quant Spectrosc Radiat Transfer 2015;152:1-15. https://doi.org/10.1016/j.jqsrt.2014.10.020.

30. Tan Y, Mikhailenko SN, Wang J, Liu A-W, Liu G-L, Zhao X-Q, Hu S-M. CRDS absorption spectrum of ${ }^{17} \mathrm{O}$ enriched water vapor in the $12,277-12,894 \mathrm{~cm}^{-1}$ range. J Quant Spectrosc Radiat Transfer 2018;221:233-42. https://doi.org/10.1016/j.jqsrt.2018.10.009.

31. Kassi S, Stoltmann T, Casado M, Daëron M, Campargue A. Lamb dip CRDS of highly saturated transitions of water near $1.4 \mu \mathrm{m}$. J Chem Phys 2018;148:054201. https://doi.org/10.1063/1.5010957.

32. Régalia L, Oudot C, Mikhailenko S, Wang L, Thomas X, Jenouvrier A, Von der Heyden P. Water vapor line parameters from 6450 to $9400 \mathrm{~cm}^{-1}$. J Quant Spectrosc Radiat Transfer 2014;136:11936. https://doi.org/10.1016/j.jqsrt.2013.11.019.

33. Toth RA. Line positions and strengths of HDO between 6000 and $7700 \mathrm{~cm}^{-1}$. J Mol Spectrosc 1997;186:66-89. https://doi.org/10.1006/jmsp.1997.7398. 
34. Toth RA. Measurements of HDO between 4719 and $5843 \mathrm{~cm}^{-1}$. J Mol Spectrosc 1997;186:276-92. https://doi.org/10.1006/jmsp.1997.7451.

35. Naumenko OV, Voronina S, Hu SM. High resolution Fourier transform spectrum of HDO in the $7500-8200 \mathrm{~cm}^{-1}$ region: revisited. J Mol Spectrosc 2004;227:151-7. https://doi.org/10.1016/j.jms.2004.06.002.

36. Tolchenov RN, Tennyson J. Water line parameters for weak lines in the range $7400-9600 \mathrm{~cm}^{-1}$. J Mol Spectrosc 2005;231:23-7. https://doi.org/10.1016/j.jms.2004.12.001.

37. Jenouvrier A, Daumont L, Régalia-Jarlot L, TyuterevVlG, Carleer M, Vandaele AC, et al. Fourier transform measurements of water vapor line parameters in the $4200-6600 \mathrm{~cm}^{-1}$ region. J Quant Spectrosc Radiat Transfer 2007;105:326-55. https://doi.org/10.1016/j.jqsrt.2006.11.007.

38. Mikhailenko SN, Tashkun SA, Putilova TA, Starikova EN, Daumont L, Jenouvrier A, et al. Critical evaluation of rotation-vibration transitions and an experimental dataset of energy levels of $\mathrm{HD}^{18} \mathrm{O}$. J Quant Spectrosc Radiat Transfer 2009;110:597-608. https://doi.org/10.1016/j.jqsrt.2009.01.012.

39. Mikhailenko SN, Tashkun SA, Daumont L, Jenouvrier A, Carleer M, Fally S, Vandaele AC. Line positions and energy levels of the 18-O substitutions from the $\mathrm{HDO} / \mathrm{D}_{2} \mathrm{O}$ spectra between 5600 and $8800 \mathrm{~cm}^{-1}$. J Quant Spectrosc Radiat Transfer 2010;111:2185-96. https://doi.org/10.1016/j.jqsrt.2010.01.028.

40. Mikhailenko SN, Naumenko OV, Nikitin AV, Vasilenko IA, Liu A-W, Song K-F et al. Absorption spectrum of deuterated water vapor enriched by ${ }^{18} \mathrm{O}$ between 6000 and $9200 \mathrm{~cm}^{-1}$. J Quant Spectrosc Radiat Transfer 2012;113:653-69. https://doi.org/10.1016/j.jqsrt.2012.02.009.

41. Régalia L, Thomas X, Rennesson T, Mikhailenko S. Line parameters of water vapour enriched by ${ }^{18} \mathrm{O}$ from 6525 to $8011 \mathrm{~cm}^{-1}$. J Quant Spectrosc Radiat Transfer 2019;235:257-71. https://doi.org/10.1016/j.jqsrt.2019.06.031.

42. Serdyukov VI, Sinitsa LN, Mikhailenko SN. FTS absorption spectrum of ${ }^{17} \mathrm{O}$ enriched water vapour between 7900 and $9500 \mathrm{~cm}^{-1}$. J Quant Spectrosc Radiat Transfer (in preparation)

43. Naumenko O, Leshchishina O, Campargue A. High sensitivity absorption spectroscopy of HDO by ICLAS-VeCSEL between 9100 and $9640 \mathrm{~cm}^{-1}$. J Mol Spectrosc 2006;236:58-69. https://doi.org/10.1016/j.jms.2005.12.008.

44. Mondelain D, Kassi S, Sala T, Romanini D, Marangoni M, Campargue A. Sub-MHz accuracy measurement of the $\mathrm{S}(2)$ 2-0 transition frequency of $\mathrm{D}_{2}$ by comb-assisted cavity ring down spectroscopy. J Mol Spectrosc 2016;326:5-8. https://doi.org/10.1016/j.jms.2016.02.008.

45. Kassi S, Campargue A. Cavity Ring Down Spectroscopy with $5 \times 10^{-13} \mathrm{~cm}^{-1}$ sensitivity. J Chem Phys 2012;137:234201. https://doi.org/10.1063/1.4769974.

46. Konefał M, Mondelain D, Kassi S, Campargue A. High sensitivity spectroscopy of the $\mathrm{O}_{2}$ band at $1.27 \mu \mathrm{m}$ : (I) pure $\mathrm{O}_{2}$ line parameters above $7920 \mathrm{~cm}^{-1}$. J Quant Spectrosc Radiat Transfer 2020;241:106653. https://doi.org/10.1016/j.jqsrt.2019.106653.

47. Gordon IE, Rothman LS, Hill C, Kochanov RV, Tan Y, Bernath PF, et al. The HITRAN2016 molecular spectroscopic database. J Quant Spectrosc Radiat Transfer 2017;203:3-69. https://doi.org/10.1016/j.jqsrt.2017.06.038.

48. Polyansky OL, Kyuberis AA, Zobov NF, Tennyson J, Yurchenko SN, Lodi L. ExoMol molecular line lists. XXX: a complete high-accuracy line list for water. Mon Not R Astron Soc 2018;480:2597-608. https://doi.org/10.1093/mnras/sty1877.

49. Tashkun SA. Institute of Atmospheric Optics SB RAS. 2007. http://spectra.iao.ru/molecules/simlaunch?mol=1

50. Partridge H, Schwenke DW. The determination of an accurate isotope dependent potential energy surface for water from extensive $a b$ initio calculations and experimental data. J Chem Phys 1997;106:4618-39. https://doi.org/10.1063/1.473987.

51. Schwenke DW, Partridge H. Convergence testing of the analytic representation of an ab initio dipole moment function for water: Improved fitting yields improved intensities. J Chem Phys 2000;113:6592-7. https://doi.org/10.1063/1.1311392.

52. Mikhailenko SN, Kassi S, Mondelain D, Gamache RR, Campargue A. A spectroscopic database for water vapor between 5850 and $8340 \mathrm{~cm}^{-1}$. J Quant Spectrosc Radiat Transfer 2016;179:198216. https://doi.org/10.1016/j.jqsrt.2016.03.035. 
53. Barber RJ, Tennyson J, Harris GJ, Tolchenov RN. A high-accuracy computed line list. Mon Not R Astron Soc 2006;368:1087-94. https://doi.org/10.1111/j.1365-2966.2006.10184.x.

54. Campargue A, Mikhailenko S, Liu AW. ICLAS of water in the $770 \mathrm{~nm}$ transparency window $\left(12746-13558 \mathrm{~cm}^{-1}\right)$. Comparison with current experimental and calculated databases. J Quant Spectrosc Radiat Transfer 2008;109:2832-45. https://doi.org/10.1016/j.jqsrt.2008.07.003.

55. Rothman LS, Gordon IE, Babikov Y, Barbe A, Benner DC, Bernath PF, et al. The HITRAN2012 molecular spectroscopic database. J Quant Spectrosc Radiat Transf 2013;130:4-50. https://doi.org/10.1016/j.jqsrt.2013.07.002

56. Tolchenov RN, Tennyson J, Brault JW, Canas AAD, Schermaul R. Weak line water vapor spectrum in the 11787-13554 $\mathrm{cm}^{-1}$ region. $\mathrm{J}$ Mol Spectrosc 2002;215:269-74. https://doi.org/10.1006/jmsp.2002.8653.

57. Tolchenov R, Tennyson J. Water line parameters from refitted spectra constrained by empirical upper state levels: study of the $9500-14500 \mathrm{~cm}^{-1}$ region. J Quant Spectrosc Radiat Transf 2008;109:559-68. https://doi.org/10.1016/j.jqsrt.2007.08.001

58. Tobias R, Furtenbacher T, Császár AG, Naumenko OV, Tennyson J, Flaud J-M, et al. Critical evaluation of measured rotational-vibrational transitions of four sulphur isotopologues of $\mathrm{S}^{16} \mathrm{O}_{2} . \mathrm{J}$ Quant Spectrosc Radiat Transfer 2018;208:152-63. https://doi.org/10.1016/j.jqsrt.2018.01.006.

59. Chubb KL, Joseph M, Franklin J, Choudhury N, Furtenbacher T, Császár AG, et al. MARVEL analysis of the measured high-resolution rovibrational spectra of $\mathrm{C}_{2} \mathrm{H}_{2}$. J Quant Spectrosc Radiat Transfer 2018;204:42-55. https://doi.org/10.1016/j.jqsrt.2017.08.018.

60. Chubb KL, Naumenko O, Keely S, Bartolotto S, MacDonald S, Mukhtar M, et al. MARVEL analysis of the measured high-resolution rovibrational spectra of $\mathrm{H}_{2}{ }^{32} \mathrm{~S}$. J Quant Spectrosc Radiat Transfer 2018;218:178-86. https://doi.org/10.1016/j.jqsrt.2018.07.012.

61. Furtenbacher T, Coles PA, Tennyson J, Yurchenko SN, Yu S, Drouin B, et al. Empirical rovibrational energy levels of ammonia up to $7500 \mathrm{~cm}^{-1}$. J Quant Spectrosc Radiat Transfer 2020;251:107027. https://doi.org/10.1016/j.jqsrt.2020.107027.

62. Al-Derzi AR, Tennyson J, Yurchenko SN, Melosso M, Jiang N, Puzzarini C, et al. An improved rovibrational linelist of formaldehyde, $\mathrm{H}_{2}{ }^{12} \mathrm{C}^{16} \mathrm{O}$. J Quant Spectrosc Radiat Transfer 2021;266:107563. https://doi.org/10.1016/j.jqsrt.2021.107563. 